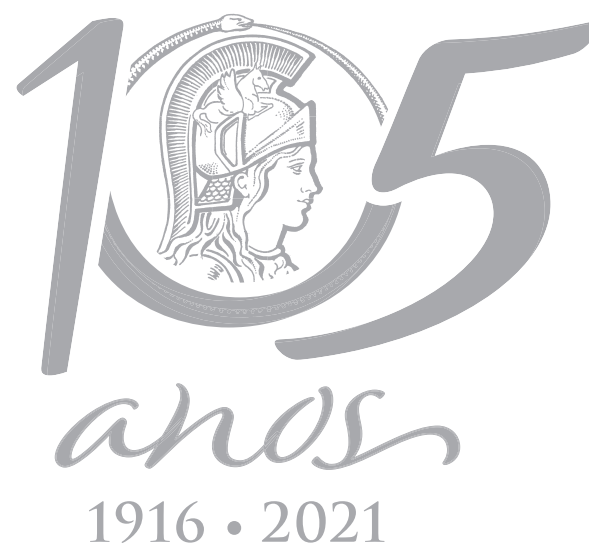

\title{
Investigation of the association of virulence genes and biofilm production with infection and bacterial colonization processes in multidrug-resistant Acinetobacter spp.
}

\author{
ADRIANA MARIA C.M. DA SILVA, SÉRGIO D. COSTA JÚNIOR, JAILTON L.C. LIMA, \\ JOSÉ LUCIANO B. DE FARIAS FILHO, ISABELLA M.F. CAVALCANTI \& MARIA AMÉLIA \\ V. MACIEL
}

\begin{abstract}
The aim of this study was to evaluate the phenotypic and molecular patterns of biofilm formation in infection and colonization isolates of Acinetobacter spp. from patients who were admitted in a public hospital of Recife-PE-Brazil in 2018-2019. For the biofilm phenotypic analysis, Acinetobacter spp. isolates were evaluated by the crystal violet staining method; the search of virulence genes (bap, ompA, epsA, csuE and bfmS) was performed by PCR; and the ERIC-PCR was performed for molecular typing. Amongst the 38 Acinetobacter spp. isolates, 20 were isolated from infections and 18 from colonization. The resistance profile pointed that $86.85 \%(33 / 38)$ of the isolates were multidrug-resistant, being three infection isolates, and two colonization isolates resistant to polymyxin $\mathrm{B}$. All the isolates were able to produce biofilm and they had at least one of the investigated virulence genes on their molecular profile, but the bap gene was found in $100 \%$ of them. No clones were detected by ERIC-PCR. There was no correlation between biofilm formation and the resistance profile of the bacteria, neither to the molecular profile of the virulence genes. Thus, the ability of Acinetobacter spp. to form biofilm is probably related to the high frequency of virulence genes.
\end{abstract}

Key words: Acinetobacter spp., bacterial colonization, biofilm, ERIC-PCR, hospital-acquired infection, virulence genes.

\section{INTRODUCTION}

The genus Acinetobacter is constituted by Gram-negative coccobacilli which are strictly anaerobic, immobile, non-fermentative, catalase positive and oxidase negative (Lee et al. 2017). Amongst the 63 validly named species, Acinetobacter baumannii is the most clinically relevant pathogen. Along with the species Acinetobacter pitti, Acinetobacter nosocomialis, Acinetobacter calcoaceticus, Acinetobacter seifertii and Acinetobacter dijkshoorniae, it constitutes the Acinetobacter calcoaceticus-baumannii (ACB) complex, and it is a pathogen potentially associated to healthcare-associated infections (HAI) (Nemec et al. 2015, Vijayakumar et al. 2019).

Acinetobacter spp. strains, especially Acinetobacter baumannii, are considered a threat to public health in a global scenario mainly due to its tendency of acquiring resistance mechanisms. This feature favors its survival even under the use of selective antimicrobial agents, and therefore, disseminates multidrugresistant strains (Reena et al. 2017). In Brazil, it was observed that the rate of Acinetobacter spp. 
which were resistant to carbapenems was $77.7 \%$ on adult intensive care units (ICUs), being the highest rate among Gram-negative bacilli (Brasil 2017). Besides that, Acinetobacter spp. has the ability of forming biofilm, which is one of the main virulence factors involved in bacterial resistance to antimicrobial agents, as it also facilitates bacterial colonization, treatment complications and persistence of these pathogens in hospitals and medical equipment (Lee et al. 2017).

The biofilm consists in a microbial community attached to the involved surface by an extracellular matrix (Flemming et al. 2016). The ability of bacterial adhesion, and the formation and development of the biofilm involve complex regulatory networks which coordinate the gene expression related to adhesion, motility and synthesis of the matrix components (RumboFeal et al. 2013). Among the virulence genes related to biofilm formation in Acinetobacter spp., the genes bap, ompA, epsA, csuE and bfms can be highlighted (Thummeepak et al. 2016, Zeighami et al. 2019).

Pilis production is required for biofilm formation (Amin et al. 2019). This structure is formed through the secretion system CsuA/ BABCDE, regulated by the two-component system bfmRS, which is relevant for both formation and maintenance of Acinetobacter spp. biofilm on inanimate surfaces (Harding et al. 2018). The gene csuE encodes part of the assembling system Csu-pilis and acts as an adhesin that binds to the surface in the beginning of the biofilm formation process (Turton et al. 2007). Besides that, the protein OmpA, among other functions in bacterial pathogenesis, acts on the adhesion between the pathogen and the human epithelial cells, and the extracellular exopolysaccharide (EPS) encoded by the gene epsA is also involved on the cell-surface and cellcell adhesion, protecting the bacteria against the defense mechanisms of the host. Both of them induce biofilm formation (Thummeepak et al. 2016).

The Bap protein, encoded by the bap gene, is a surface adhesin involved on the intracellular adhesion in mature biofilm and biomass volume. This protein is considered a key component for biofilm formation in A. baumannii and it might also have a role on the infection persistence caused by the bacteria (Rumbo-Feal et al. 2013).

The prevalence of colonization cases by A. baumannii are higher when compared to infection (Martins \& Barth 2013). The ability of colonizing, combined to the multidrug resistance of this microorganism, constitute predisposing factors to the development or aggravation of infections, and also, favor the survival of the pathogen and its dissemination in hospital units (Badave \& Kulkarni 2015, Ryu et al. 2017).

Therefore, the present study aimed to phenotypically characterize biofilm formation in infection and colonization isolates of Acinetobacter spp., and to verify the occurrence of virulence genes (bap, ompA, epsA, csuE and bfms), describing the clonal relationships among the isolates.

\section{MATERIALS AND METHODS}

\section{Bacterial isolates}

Acinetobacter spp. isolates were acquired from patients admitted in different sectors of a public hospital in Recife, Pernambuco, Brazil. The isolates were harvested from surveillance culture samples and infection sites during the period of November, 2018 to January, 2019. The definitions of colonization and infection followed the clinical and microbiological criteria of the hospital. The clinical isolates were sent to the Bacteriology and Molecular Biology Laboratory of the Medical Science Center/UFPE, where they were conserved in glycerol and stored at $-80^{\circ} \mathrm{C}$. 
The bacteria were reactivated after incubation in test tubes containing brainheart infusion (BHI) broth at $35 \pm 2{ }^{\circ} \mathrm{C}$ for 48 hours. Then, they were seeded in Luria Bertani (LB) medium and incubated at $35 \pm 2{ }^{\circ} \mathrm{C}$ for 24 hours. Regarding bacterial identification, Acinetobacter spp. isolates were identified by the automated system BD Phoenix ${ }^{\circledR}$ prior to acquisition, and afterwards, submitted to a molecular identification through the detection of the bla $a_{\text {oxa-51-like }}$ gene to confirm the species $A$. baumannii, according to Woodford et al. (2006).

\section{Susceptibility profile to antimicrobial agents}

The susceptibility analysis of the isolates was performed through the automated system BD Phoenix ${ }^{\oplus}$, which tested the antimicrobial agents amikacin, cefepime, ceftazidime, ceftriaxone, ciprofloxacin,gentamicin,imipenem,levofloxacin, meropenem, piperacillin/tazobactam and trimethoprim + sulfamethoxazole. Afterwards, the minimum inhibitory concentration (MIC) of polymyxin B to Acinetobacter spp. isolates was determined through the broth microdilution assay, according to the Clinical and Laboratory Standards Institute (CLSI 2019). Escherichia coli NCTC 13846 was used as the positive control and Pseudomonas aeruginosa ATCC 27853 and E. coli ATCC 25922 were used as negative controls. All the experiments were performed in triplicate in three independent days.

The isolates were considered multidrug resistant (MDR), multidrug sensitive (MDS) and the extensively drug resistant (XDR) according to Magiorakos et al. (2012).

\section{Phenotypic characterization of biofilm formation}

To evaluate biofilm formation, the crystal violet staining method was used according to Stepanović et al. (2000). Acinetobacter spp. isolates were cultured in Tryptic Soy Broth (TSB) at $35 \pm 2{ }^{\circ} \mathrm{C}$ for 24 hours. The microtitration was performed in triplicate in three independent days using 96-well flat-bottom polystyrene plates, where $200 \mu \mathrm{L}$ of the bacterial suspensions at 0.5 on the McFarland scale were added, using the TSB broth without inoculum as the negative control. As the positive control, the strain A. baumannii ATCC 19606 was used. The plates were then incubated at $35 \pm 2{ }^{\circ} \mathrm{C}$ for 24 hours. After this period, the bacterial suspensions were removed, and each well was washed 3 times with $250 \mu \mathrm{L}$ of a sterile $0.9 \% \mathrm{NaCl}$ solution. Then, the fixation was performed with $200 \mu \mathrm{L}$ of $99 \%$ methanol for 15 minutes. After that, the methanol was removed, the plates were dried at room temperature and further stained with 200 $\mu \mathrm{L}$ of $1 \%$ crystal violet solution for 20 minutes. The plates were then washed with running water and dried at room temperature. After this process, the plates were read in an ELISA plate reader (BioRad, model 550) at $570 \mathrm{~nm}$ wavelength. The values of the optical densities of each isolate (ODi) were obtained by the mean of the triplicates, comparing this value with the optical density of the negative control (ODC). The isolates were classified in four categories according to the mean optical densities (OD) related to the results obtained for the ODC. The categories were based on the following criteria: non adherent if ODi $\leq$ ODc; weakly adherent $(+)$ if ODC < ODi $\leq 2 \times$ ODc; moderately adherent $(++)$ if $2 \times O D C<O D i \leq 4 \times O D c$; or strongly adherent $(+++)$ if $4 \times$ ODC $<$ ODi.

\section{Total DNA extraction}

After incubating the isolates in Luria Bertani (LB) broth at $35 \pm 2{ }^{\circ} \mathrm{C}$ for 24 hours, the total DNA extraction was performed using the Brazol kit (LGC-Biotechnology), according to the manufacturer's instructions. The extracted DNA was quantified (NanoDrop 2000c, Thermoscientific ${ }^{\circledR}$ ) and stored at $-20^{\circ} \mathrm{C}$. 


\section{Detection of virulence genes}

The presence of the virulence genes bap, ompA, epsA, csuE and bfmS was detected through polymerase chain reaction (PCR) with the primers and amplification conditions described on Table I. Each reaction was prepared in a final volume of $25 \mu \mathrm{L}$ per tube, which comprised of $20 \mathrm{ng}(2 \mu \mathrm{L})$ of the total DNA, $15 \mathrm{pmol}(1 \mu \mathrm{L})$ of each primer, $0.6 \mu \mathrm{L}$ of deoxyribonucleotide triphosphate (dNTP) (8 mM), $5.0 \mathrm{~mL}$ of buffer (5x), $2.0 \mathrm{~mL}$ of $\mathrm{MgCl}_{2}(25 \mathrm{mM})$ and $0.2 \mu \mathrm{L}$ of Taq DNA Polimerase (5U). The PCR products were submitted to electrophoresis in a $1 \%$ agarose gel with $0.5 \times$ TBE buffer, and after staining with blue-green (LGC Biotecnology, São Paulo, Brazil) , they were visualized and photodocumented in an ultra-violet transilluminator (Kasviं, Brazil).

Table l. List of primers and amplification conditions for the search of virulence genes in Acinetobacter spp.

\begin{tabular}{|c|c|c|c|c|}
\hline Gene & Oligonucleotide sequence $\left(5^{-}-3^{\prime}\right)$ & Amplification condition & $\begin{array}{l}\text { Amplicon } \\
\text { (bp) }\end{array}$ & Reference \\
\hline Вар & $\begin{array}{l}\text { F: TACTTCCAATCCAATGCTAGGGAGGGTACCAATGCAG } \\
\text { R: TTATCCACTTCCAATGATCAGCAACCAAACCGCTAC }\end{array}$ & $\begin{array}{l}\text { Initial denaturation } 96{ }^{\circ} \mathrm{C} \text {, } \\
5 \text { min, } \\
\text { 35x: } 96^{\circ} \mathrm{C}, 1 \mathrm{~min} ; 56.5^{\circ} \mathrm{C}, 1 \\
\text { min; } 72{ }^{\circ} \mathrm{C}, 1 \mathrm{~min}, \\
\text { Final extension: } 72{ }^{\circ} \mathrm{C}, 10 \\
\text { min }\end{array}$ & 1225 & $\begin{array}{l}\text { Goh et al. } \\
\text { (2013) }\end{array}$ \\
\hline CSUE & $\begin{array}{l}\text { F: ATGCATGTTCTCTGGACTGATGTTGAC } \\
\text { R: CGACTTGTACCGTGACCGTATCTTGATAAG }\end{array}$ & $\begin{array}{l}\text { Initial denaturation } 96{ }^{\circ} \mathrm{C} \text {, } \\
5 \text { min, } \\
\text { 35x: } 96^{\circ} \mathrm{C}, 1 \mathrm{~min} ; 57^{\circ} \mathrm{C}, 1 \\
\text { min; } 72{ }^{\circ} \mathrm{C}, 1 \mathrm{~min}, \\
\text { Final extension: } 72{ }^{\circ} \mathrm{C}, 10 \\
\text { min }\end{array}$ & 976 & $\begin{array}{l}\text { Turton et } \\
\text { al. (2007) }\end{array}$ \\
\hline ompA & $\begin{array}{l}\text { F: CGCTTCTGCTGGTGCTGAAT } \\
\text { R: CGTGCAGTAGCGTTAGGGTA }\end{array}$ & $\begin{array}{l}\text { Initial denaturation } 94^{\circ} \mathrm{C} \text {, } \\
5 \text { min, } \\
35 x: 94^{\circ} \mathrm{C}, 1 \mathrm{~min} ; 55^{\circ} \mathrm{C}, 1 \\
\text { min; } 72{ }^{\circ} \mathrm{C}, 45 \mathrm{sec}, \\
\text { Final extension: } 72^{\circ} \mathrm{C}, 5 \\
\text { min }\end{array}$ & 531 & $\begin{array}{l}\text { Tayabali } \\
\text { et al. } \\
\text { (2012) }\end{array}$ \\
\hline$b f m S$ & $\begin{array}{l}\text { F: TTGCTCGAACTTCCAATTTATTATAC } \\
\text { R: TTATGCAGGTGCTTTTTTATTGGTC }\end{array}$ & $\begin{array}{l}\text { Initial denaturation } 94^{\circ} \mathrm{C} \text {, } \\
5 \text { min, } \\
\text { 35x: } 94^{\circ} \mathrm{C}, 1 \mathrm{~min} ; 55^{\circ} \mathrm{C}, 1 \\
\text { min; } 72{ }^{\circ} \mathrm{C}, 45 \mathrm{sec}, \\
\text { Final extension: } 72^{\circ} \mathrm{C}, 5 \\
\min \end{array}$ & 1368 & $\begin{array}{l}\text { Liou et al. } \\
\quad(2014)\end{array}$ \\
\hline epsA & $\begin{array}{l}\text { F: AGCAAGTGGTTATCCAATCG } \\
\text { R: ACCAGACTCACCCATTACAT }\end{array}$ & $\begin{array}{l}\text { Initial denaturation } 94^{\circ} \mathrm{C} \text {, } \\
5 \text { min, } \\
\text { 35x: } 94^{\circ} \mathrm{C}, 1 \text { min; } 55^{\circ} \mathrm{C}, 1 \\
\text { min; } 72{ }^{\circ} \mathrm{C}, 45 \mathrm{sec}, \\
\text { Final extension: } 72^{\circ} \mathrm{C}, 5 \\
\text { min }\end{array}$ & 451 & $\begin{array}{l}\text { Tayabali } \\
\text { et al. } \\
\text { (2012) }\end{array}$ \\
\hline
\end{tabular}

F: forward, R: reverse, bp: base pairs. 
A. baumannii ATCC 19606 was used as a positive control.

\section{Enterobacterial Repetitive Intergenic Consensus (ERIC-PCR)}

The search for the genetic relationship between the isolates was performed through ERIC-PCR. The reactions were prepared in a total volume of $25 \mu \mathrm{L}$ per tube, corresponding of: $100 \mathrm{ng}$ of the genomic DNA, 10 pmol of the primers (ERIC1 [5'- ATGTAAGCTCCTGGGGATTCAC-3']; ERIC-2 [5'-AAGTAAGTGACTGGGGTG AGCG-3']), Buffer (1x), $200 \mu \mathrm{M}$ of deoxyribonucleotide triphosphate, 1.5 $\mathrm{mM}$ of $\mathrm{MgCl}_{2}$ and $1 \mathrm{U}$ of Taq DNA polymerase. The amplification parameters used for the ERIC-PCR were: initial denaturation at 95 oC for 3 minutes, followed by 30 cycles of denaturation at $92{ }^{\circ} \mathrm{C}$ for 1 minute, annealing at $36^{\circ} \mathrm{C}$ for 1 minute and extension at $72{ }^{\circ} \mathrm{C}$ for 8 minutes. After the 30 cycles, a final extension of 16 minutes at $72{ }^{\circ} \mathrm{C}$ was performed. The PCR products were stained with blue-green (LGC Biotecnology, São Paulo, Brazil) and submitted to electrophoresis in a 1.5\% agarose gel, visualized and photodocumented under UV light (Kasvi', Brazil) (Duan et al. 2009). The data analysis and dendrogram constructions were performed using the software Past. The similarity adopted to define the clonal relationship amongst the Acinetobacter spp. strains was equal or higher than $85 \%$.

\section{Statistical analysis}

The statistical analyzes were conducted using the software Graphpad prism 8.3.1. The sample description was performed by frequency with a 95\% confidence interval $\left(\mathrm{Cl}_{95 \%}\right)$. The difference of the biofilm's biomass among infection and colonization isolates was compared using the Student's t-test. The Chi-squared test was used to analyze the differences between the frequencies of virulence genes related to biofilm formation. P values <0.05 were considered statistically significant.

\section{Ethics approval}

This study was approved by the Ethics Committee of the Health Sciences Center - Federal University of Pernambuco, under the number: CAAE 0490.0.172.000-11.

\section{RESULTS}

A total of 38 isolates of Acinetobacter spp. from patients admitted in a public hospital in RecifePE, Brazil, were collected between 2018 and 2019. Among them, 20 were infection isolates, being 45\% (9/20) from tracheal secretion, 30\% (6/20) from blood, 20\% (4/20) from catheter tips and $5 \%(1 / 20)$ from urine. The remaining18isolates were collected from surveillance cultures, being 94.44\% (17/18) from rectal swab and 5.56\% (1/18) from nasal swab, characterized as colonization isolates. The species Acinetobacter baumannii was identified in $81.58 \%(31 / 38)$ of the isolates in this study by investigating the presence of the bla $a_{\text {oxa-51-like }}$ gene. The seven strains which were negative for the bla $a_{\text {OXA-51-like }}$ gene were identified as being from the Acinetobacter calcoaceticusbaumannii ( $A C B$ ) complex, according to the analysis on BD Phoenix.

The antimicrobial susceptibility profiles of Acinetobacter spp. isolates are described on Figure 1. All 38 isolates were resistant to third-generation cephalosporins (ceftazidime and ceftriaxone), piperacillin/tazobactam, fluoroquinolones (ciprofloxacin and levofloxacin) and carbapenems (imipenem and meropenem). Based on the resistance profile of the isolates evaluated in this study, 86.85\% (33/38) were characterized as MDR. Both infection and colonization isolates had a resistance rate to amikacin and cefepime equal or higher than 
a)

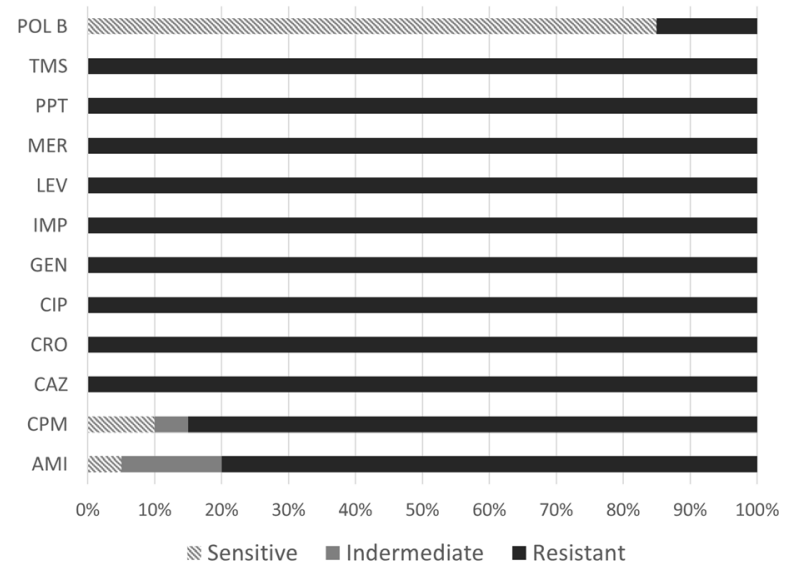

b)

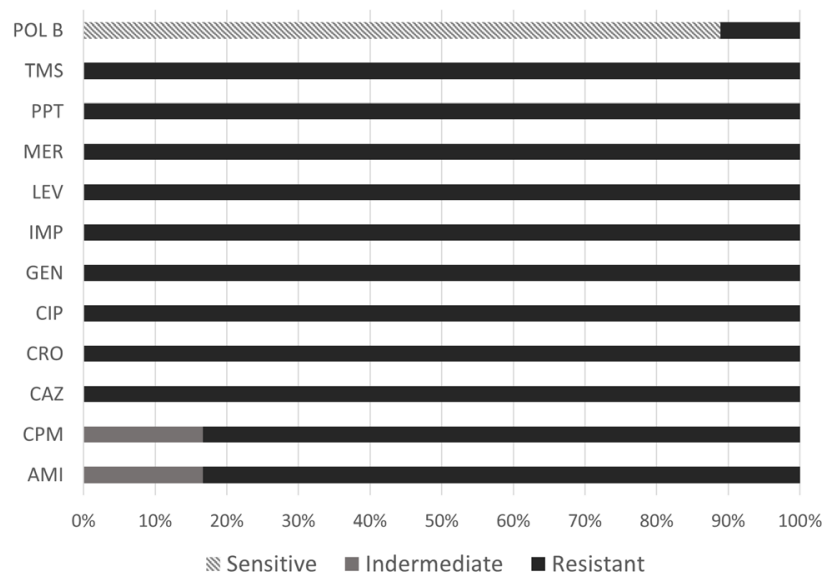

Figure 1. Percentage representation of antimicrobial susceptibility profiles of Acinetobacter spp. isolates in Recife - PE - Brazil. a) Infection isolates and b) Colonization isolates. AMI: amikacin; GEN: gentamycin; IMP: imipenem; MER: meropenem; CIP: ciprofloxacin; LEV: levofloxacin; CPM: cefepime; CAZ: ceftazidime; CRO: ceftriaxone; PPT: piperacillin/tazobactam; TRI/SUL: trimethoprim + sulfamethoxazole; POL B: polymyxin B.

$80 \%$. Besides that, the MIC values of polymyxin $B$ determined by the broth microdilution assay varied from 0.125 to $32 \mu \mathrm{g} / \mathrm{mL}$, being 85\% (17/20) and $88.88 \%(16 / 18)$ classified as sensitive isolates from infection and colonization, respectively. Therefore, although most clinical Acinetobacter spp. isolates presented growth inhibition against polymyxin $\mathrm{B}$ at concentrations of 0.25 to $1 \mu \mathrm{g} / \mathrm{mL}, 15 \%$ (3/20) of the infection isolates and $11.11 \%(2 / 18)$ of the colonization isolates were resistant to polymyxin $B$, being classified as XDR.

Through the evaluation of the phenotypic profiles of Acinetobacter spp. biofilms, it was demonstrated that all 38 isolates had different adherence intensities. The comparison between biofilm formation among infection and colonization isolates of Acinetobacter spp. according to the intensity categories of adherence, did not present statistical significance by the Student's t-test ( $p=0.378 ; \mathrm{Cl}_{95 \%}$ -0.015 - 0.039), as it can be observed on Figure 2. Amongst the 20 infection isolates, 5 (25\%) were characterized as weakly adherent (3 MDR and 2 XDR), 11 (55\%) as moderately adherent (11 MDR) and $4(20 \%)$ as strongly adherent (3 MDR and
1 XDR). Regarding the 18 colonization isolates, $6(33.33 \%)$ were classified as weakly adherent (5 MDR and 1 XDR), 10 (55.56\%) as moderately adherent (9 MDR and 1 XDR), and $2(11.11 \%)$ as strongly adherent (2 MDR).

No statistical difference was observed when the resistance profile of the microorganism was correlated with biofilm formation according to the Chi-squared test $(p>0.05)$. Infection and colonization isolates presented similar percentages of weak, moderate and strong biofilm phenotypic profiles, as well as the XDR profile (Figure 3).

The amplification of the virulence genes (bap, ompA, csuE, bfmS and epsA) by PCR pointed that all the 38 Acinetobacter spp. clinical isolates carried at least one of these genes related to biofilm formation. The most prevalent gene was bap, which was present in all 38 Acinetobacter spp. isolates. The occurrence of the genes ompA, cSUE, bfmS and epsA among the infection isolates was of $95 \%(19 / 20), 85 \%$ (17/20), 70\% (14/20) and 65\% (13/20), respectively. Among the colonization isolates, the frequency of the virulence genes was of $94.44 \%(17 / 18)$ 


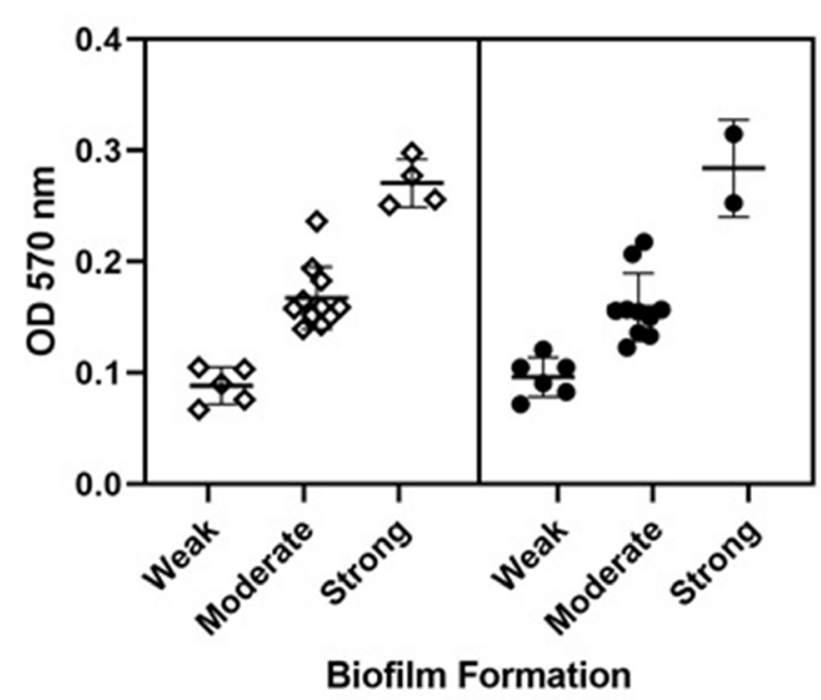

for ompA and cSUE, followed by $61.11 \%(11 / 18)$ for $b f m S$ and epsA. From all the 5 virulence genes which were studied, in $85 \%(17 / 20)$ of the infection isolates and in $94.44 \%(17 / 18)$ of the colonization isolates, the genes bap, ompA and csuE coexisted in their genetic profile.

Likewise, there was no statistical significance between infection and colonization samples when the frequency of the virulence genes (bap, ompA, epsA, csuE and bfms) and the biofilm phenotypic profile were evaluated by the Chisquared test $(p>0.05)$ (Figure 4$)$.

In the present study, the genotyping of clinical Acinetobacter spp. isolates by ERICPCR identified 38 distinct genetic profiles, with similarities ranging from $20 \%$ to $75 \%$ (Figure 5).

\section{DISCUSSION}

The incidence of HAls caused by species of the genus Acinetobacter is increasing on the global scenario, and in spite of accounting for over 50 validly named species, Acinetobacter baumannii is the predominant pathogen isolated from patients in hospital environments ( $\mathrm{Li}$ et al. 2016, Wong et al. 2017). In this study, through the phenotypic and molecular analysis of the

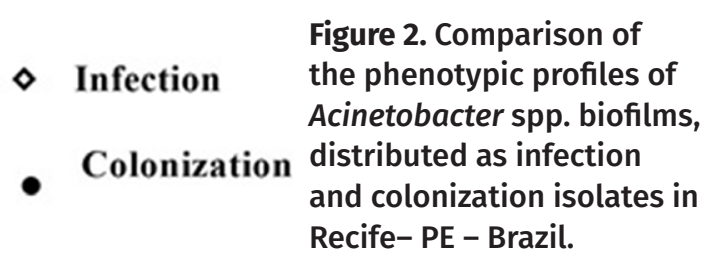

Figure 2. Comparison of the phenotypic profiles of Acinetobacter spp. biofilms, and colonization isolates in Recife- PE - Brazil. bla $a_{\text {OXA-51-like }}$ gene, $81.58 \%(31 / 38)$ of the isolates were identified as A. baumannii and $18.42 \%$ (7/38) as part of the Acinetobacter calcoaceticusbaumannii complex (ACB). In 2019, Falah et al. (2019) have reported that $97.56 \%(80 / 82)$ of $A$. baumannii isolates identified by phenotypic and biochemical tests, carried the bla $a_{\text {OXA-51 }}$ gene, confirming therefore, the identification of the isolates as A. baumannii.

The antimicrobial susceptibility profile revealed that $86.85 \%$ (33/38) of Acinetobacter spp. isolates were MDR. All the 38 isolates were resistant to third-generation cephalosporins, fluoroquinolones and carbapenems, which are considered the main therapy for infections caused by A. baumannii (Amin et al. 2019, Silva \& Domingues 2017). Both infection and colonization isolates presented a resistance rate to amikacin and to cefepime equal or higher than $80 \%$. Similar results were previously reported in studies performed in several countries, including Brazil (Badave \& Kulkarni 2015, Duarte et al. 2016, Fallah et al. 2017, Lima et al. 2020).

Inaccordancewith the high rates of resistance to carbapenems found in this study, Wasfi et al. (2021) detected resistance to carbapenems meropenem and ertapenem in 70.8\% (34/48) 

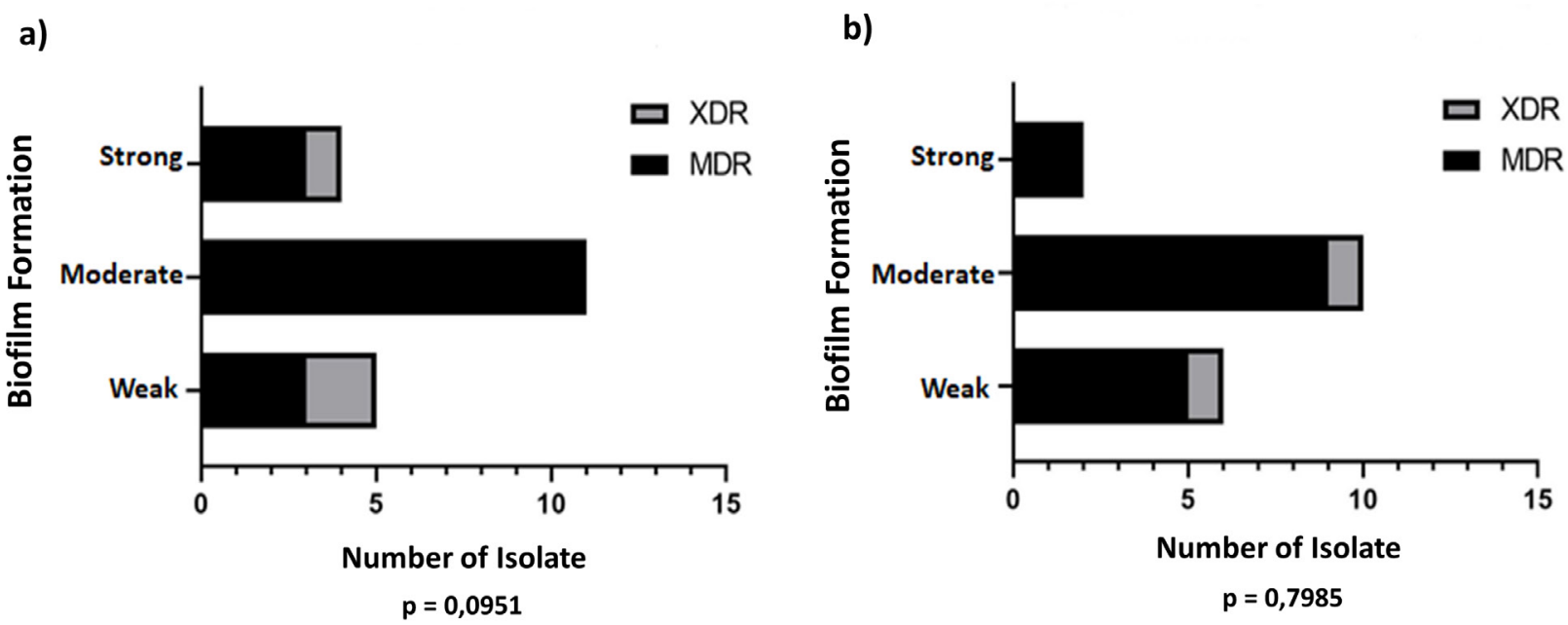

Figure 3. Correlation between biofilm formation and resistance profiles of Acinetobacter spp. isolates in Recife PE - Brazil. a) Infection isolates and b) Colonization isolates.

of A. baumannii isolates collected from blood infection samples, in cancer patients, at the National Cancer Institute ( $\mathrm{NCl}$ ), Giza, Egypt. This resistant profile presented by Gram-negative bacilli such as Acinetobacter spp. concerns the global public health because if there is a high isolation of strains which are resistant to carbapenems, the treatment options get more limited and will induce, therefore, the need of new therapeutic approaches, such as the use of polymyxins (colistin and polymyxin B) (Duarte et al. 2016). In this study, although more than $85 \%$ of the isolates were sensitive to polymyxin $\mathrm{B}, 15 \%(3 / 20)$ of the infection isolates and $11.11 \%$ $(2 / 18)$ of the colonization isolates were resistant, and thus, classified as XDR. There is a variation on the incidence or frequency of polymyxin $B$ resistance in Acinetobacter spp. isolates in Brazil. Romanin et al. (2019) pointed that 10.7\% $(11 / 103)$ of $A$. baumannii isolates harvested from blood samples of patients admitted in a hospital in Londrina - Brazil, were resistant to polymyxin B. On the other hand, Siqueira et al. (2018) identified that all 68 A. baumannii samples obtained from urine, blood and other secretions, isolated in a hospital from Espírito Santo - Brazil, were susceptible to polymyxin B.
The phenotypic analysis has indicated that all 38 Acinetobacter spp. isolates in this study were biofilm producers with similar percentages of weak, moderate and strongly adherent among infection and colonization isolates. Zeighami et al. (2019) have demonstrated that all $A$. baumannii isolates obtained from blood, thorax and urine secretions were capable of producing biofilm, however, 58\% (58/100) of these isolates were strongly adherent, whereas in the present study, the same was verified in only $20 \%(5 / 20)$ of infection isolates and in $11.11 \%(2 / 18)$ of colonization isolates. Besides that, there was no difference on the OD means of the biofilms when it was compared between isolates grouped according to the source (infection and colonization). Similarly, when biofilm formation was investigated in clinical and environmental isolates of A. baumannii in Iran, Ghasemi et al. (2018) also did not detect differences based on the sample, although environmental isolates present a higher ability of producing biofilm compared to clinical ones, what reinforces the colonization potential of this bacteria.

According to Schroeder et al. (2017), virulence is not only defined by the ability of colonization, but also for causing diseases, 
a)

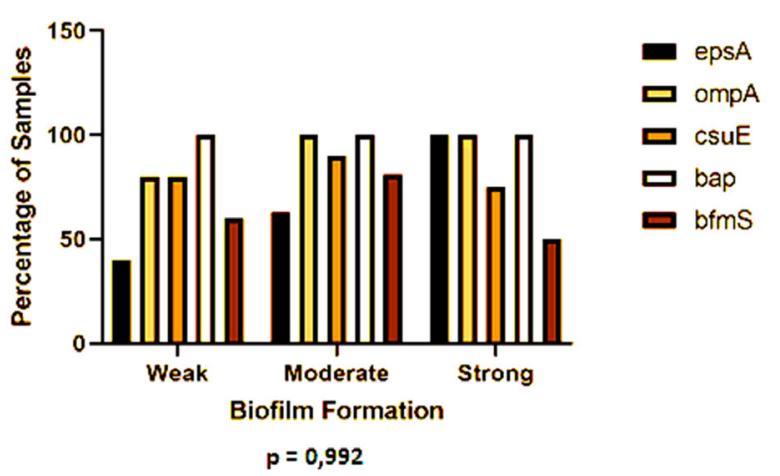

b)

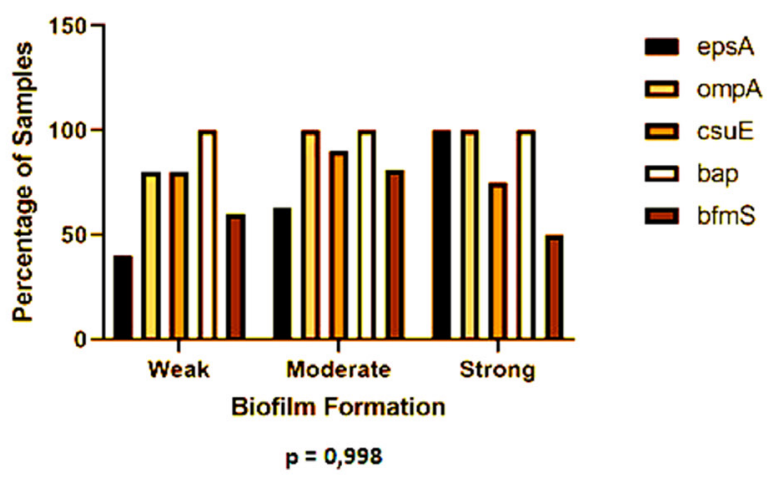

Figure 4. Comparison between biofilm formation and frequency of virulence genes in Acinetobacter spp. isolates in Recife - PE - Brazil. a) Infection isolates and b) Colonization isolates.

and the biofilm formation is an essential part of bacterial pathogenesis with evidences that its development provides a higher resistance to antimicrobial agents. While some authors have found a positive relationship between the MDR profile of $A$. baumannii isolates and biofilm formation (Badave \& Kulkarni 2015, Duarte et al. 2016, Yang et al. 2018), others have identified the opposite, in which an increased biofilm formation is higher among non-MDR isolates of A. baumannii (Aminm et al. 2019, Qi et al. 2016). Although there are divergent reports about the relationship between the resistance profile and biofilm formation, this study did not observe a significant relationship between these characteristics among Acinetobacter spp. isolates, corroborating with Lima et al. (2020), whose analysis of 35 strains of Acinetobacter baumannii harvested from tracheal secretion, urine and cerebrospinal fluid has revealed that 24 isolates (68.6\%) were strong biofilm producers (23 XDR and one non-MDR); 10 isolates (28.6\%) were moderate producers ( 9 XDR and one nonMDR); and only one isolate (2.9\%) was a weak biofilm producer with an XDR profile.

Among the virulence genes involved in biofilm formation, the bap gene was the most prevalent in this experimental study, being present in all 38 isolates of Acinetobacter spp. The high prevalence of the bap gene was also reported by Goh et al. (2013) and Liu et al. (2016), who have detected the bap gene in 91.7\% (22/24) and $95.5 \%(84 / 88)$ of $A$. baumannii strains, respectively, and have shown the importance of the Biofilm associated protein (Bap), expressed on the cell surface, contributing for the biofilm formation in vitro.

In the present study, the genes CSUE, ompA, epsA and bfms presented high frequency rates among Acinetobacter spp. isolates. Whilst the prevalence of the genes ompA and csuE ranged from $85 \%$ to $95 \%$, the prevalence of bfmS and epsA genes ranged from $61.11 \%$ to $70 \%$, with similar frequencies among infection and colonization isolates. The prevalent gene in a study performed by Zeigmani et al. (2019) was csuE, present in all 100 isolates of A. baumannii, corroborating with the high percentages found in our results. In 2016, Thummeepak et al. (2016) have described the distribution of the virulence genes ompA, bfmS and epsA in A. baumannii isolates with frequencies of $84.4 \%$ (190/225), $84 \%$ (189/225) and 22.2\% (50/225), respectively, and revealed a high prevalence of biofilm producing profiles among these isolates. 
a)

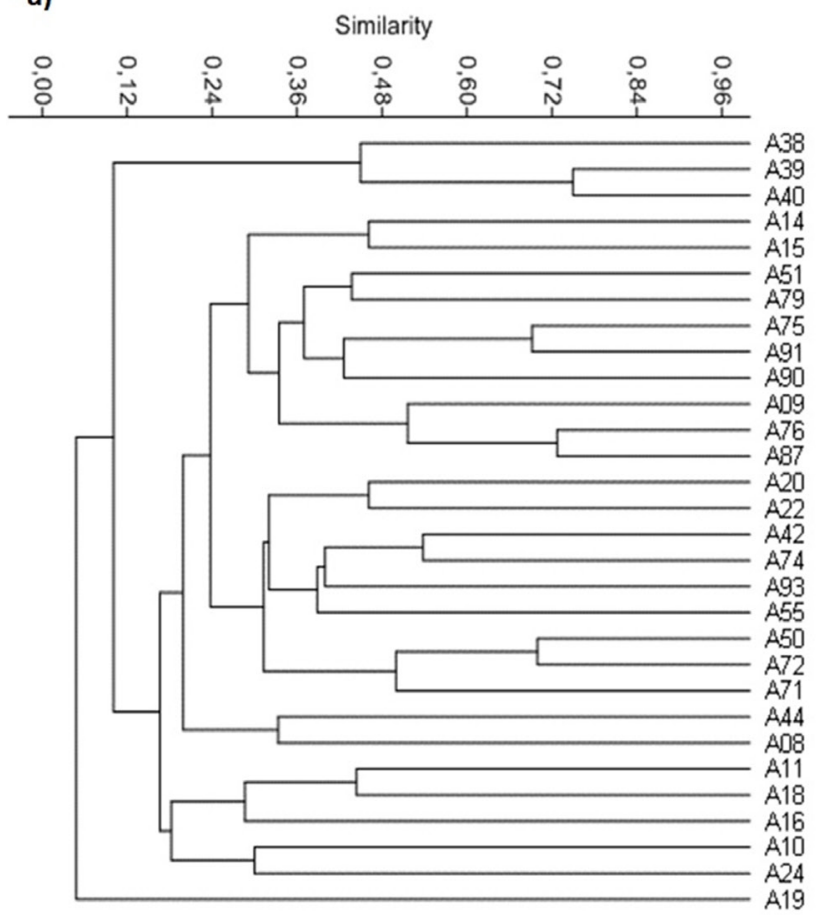

b)
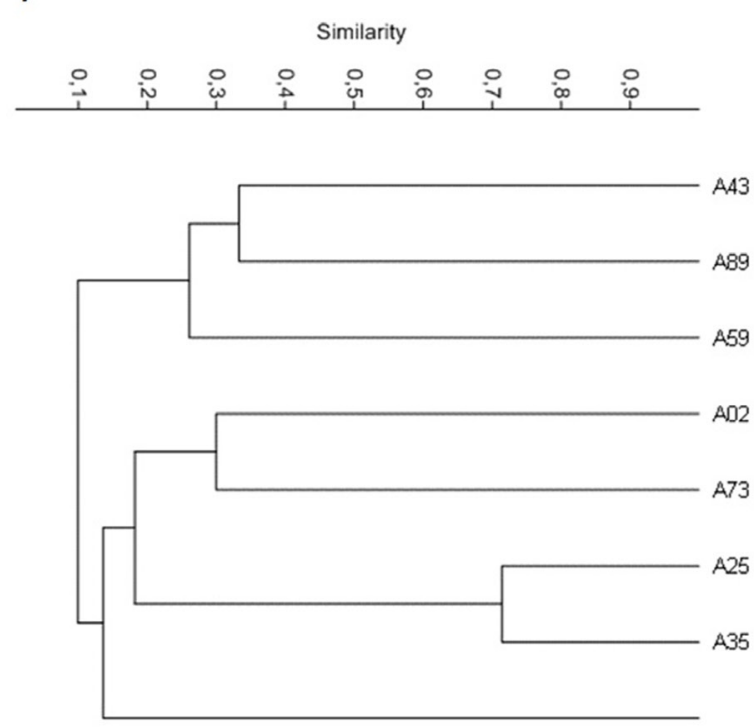

Figure 5. Dendrogram representing the patterns of Enterobacterial Repetitive Intergenic Consensus (ERIC-PCR) from Acinetobacter spp. clinical isolates in Recife - PE - Brazil. a) Acinetobacter baumannii isolates and b) Acinetobacter calcoaceticus-baumannii complex isolates.

When analyzing the correlation between biofilm formation and the related virulence genes, Yang et al. (2018) have suggested that A. baumannii strains which carry the genes bap, ompA and csuE tend to produce strongly adherent biofilms when compared to isolates without these genes. Although these genes have coexisted in $85 \%(17 / 20)$ of the infection isolates and in $94.44 \%$ (17/18) of the colonization isolates, this study did not find a significant correlation between biofilm formation and the presence of the virulence genes, neither a statistical difference when infection and colonization isolates were compared.

According to the condition of the biofilm formation, the genetic products expressed by the genes are crucial for adhesion and biofilm development, being a determinant factor on the epidemiology of infections caused by Acinetobacter spp. (Siqueira et al. 2018). Liou et al. (2014) have demonstrated that, for instance, the bfmS mutated gene decreased biofilm formation, reduced the adherence to cells and the sensitivity to serum killing of $A$. baumannii. In this case, the previous identification of virulence genes in colonization samples contaminated by Acinetobacter spp. can indicate the risk of infection in patients who are colonized with virulent isolates able to produce biofilm, since in most outbreaks of A. baumannii, colonized patients are in general, a source of initial transmission (Falah et al. 2019).

The phylogenetic relation among the isolates was investigated by ERIC-PCR. This molecular typing method was performed for being fast, reliable and of easy execution for the epidemiological elucidation of strains that circulate in hospital environments (Amin et al. 2019). According to the results, this method indicated genetic diversity and heterogeneity 
among the 38 clinical Acinetobacter spp. isolates, with a similarity ranging from $20 \%$ to $75 \%$. However, no clone was identified. Previous studies have reported the identification of clonal profiles in Acinetobacter baumannii isolates, as Moreira et al. (2018) who detected 17 different groups among 48 isolates; Falah et al. (2019) who identified 14 ERIC-PCR patterns among 80 isolates; and Heidari et al. (2018) who identified 20 ERIC-PCR types among 75 isolates. Paradoxically, although there are reports of clonality in the literature, it is also possible to recognize the level of clonal diversity among the strains of $A$. baumannii.

\section{CONCLUSIONS}

In Brazil, there is a lack of reports regarding the analysis of biofilm formation and the detection of virulence genes in Acinetobacter spp. strains. The present study has demonstrated multidrugresistant Acinetobacter spp. isolates, including those resistant to polymyxin B. It was also evidenced the high phenotypic prevalence of biofilm formation, high frequencies of virulence genes and the heterogeneity between infection and colonization isolates. Therefore, the use of surveillance cultures for the continuous monitoring of the epidemiological and susceptibility profiles to antimicrobials used against circulating microorganisms in hospital environments, could be one of many strategies to guide the therapy of nosocomial infections caused by bacteria and minimize the propagation of virulent strains.

\section{Acknowledgments}

The authors thank the financial support of the Dean's office of Research and Graduate Affairs at the Federal University of Pernambuco (PROPESQ/UFPE) and the Fundação de Amparo a Ciência e Tecnologia de Pernambuco (FACEPE) [APQ-0814-4.03/17].

\section{REFERENCES}

AMIN M, NAVIDIFAR T, SHOOSHTARI FS, RASHNO M, SAVARI M, JAHANGIRMEHR F \& ARSHADI M. 2019. Association between biofilm formation, structure, and the expression levels of genes related to biofilm formation and biofilm-specific resistance of Acinetobacter baumannii strains isolated from burn infection in Ahvaz, Iran. Infect Drug Resist 12: 3867-3881.

BADAVE GK \& KULKARNI D. 2015. Biofilm Producing Multidrug Resistant Acinetobacter baumannii: An Emerging Challenge. J Clin Diagn Res 9(1): DC08-10.

BRASIL. 2017. Agência Nacional de Vigilância Sanitária. Boletim Segurança do Paciente e Qualidade em Serviços de Saúde no 17: Avaliação dos indicadores nacionais das Infecções Relacionadas à Assistência à Saúde (IRAS) e Resistência microbiana do ano de 2017. 6. Brasília: Anvisa; 2017. http://portal.anvisa.gov. br/documents/33852/3074203/Boletim+Seguran\%C3 $\% A 7 a+d o+$ Paciente $+e+Q$ ualidade+em+Servi\%C3\%A7o $\mathrm{s}+\mathrm{de}+\mathrm{Sa} \%$ C3\%BAde+n+17/c0d5caa9-45b9-4861-b07bb82b40b3334f. Accessed 16 dez 2019.

CLSI. 2019. Performance Standards for Antimicrobial Susceptibilly Testing. Clinical and Laboratory Standars Institute, Wayne, PA, USA, $29^{\text {th }}$ edition.

DUAN H ET AL. 2009. Source identification of airborne Escherichia coli of swine house surroundings using ERIC-PCR and REP-PCR. Environ Res 109(5): 511-517.

DUARTE A, FERREIRA S, ALMEIDA S \& DOMINGUES FC. 2016. Clinical isolates of Acinetobacter baumannii from a Portuguese hospital: PFGE characterization, antibiotic susceptibility and biofilm-forming ability. Comp Immunol Microbiol Infect Dis 45: 29-33.

FALAH F, SHOKOOHIZADEH L \& ADABI M. 2019. Molecular identification and genotyping of Acinetobacter baumannii isolated from burn patients by PCR and ERICPCR. Scars, Burns \& Healing 5: 1-7.

FALLAH A, REZAEE MA, HASANI A, BARHAGHI MHS \& KAFIL HS. 2017. Frequency of bap and cpaA virulence genes in drug resistant clinical isolates of Acinetobacter baumannii and their role in biofilm formation. Iran J Basic Med Sci 20(8): 849-855.

FLEMMING HC, WINGENDER J, SZEWZYK U, STEINBERG P, RICE SA \& KJELLEBERG S. 2016. Biofilms: an emergent form of bacterial life. Nat Rev Microbiol 14(9): 563-575.

GHASEMI E, GHALAVAND Z, GOUDARZI H, YEGANEH F, HASHEMI A, DABIRI H, MIRSAMADI FS \& FOROUMAND M. 2018. Phenotypic and genotypic investigation of biofilm formation in 
clinical and environmental isolates of Acinetobacter baumannii. Arch Clin Infect Dis 13(4): e12914.

GOH HM ET AL. 2013. Molecular analysis of the Acinetobacter baumannii biofilm associated protein. Appl Environ Microbiol 79(21): 6535-6543.

HARDING CM, HENNON SW \& FELDMAN MF. 2018. Uncovering the mechanisms of Acinetobacter baumannii virulence. Nat Rev Microbiol 16(2): 91-102.

HEIDARI, H, HALAJI M, TAJI A, KAZEMIAN H, SHAMSABADI MS, SISAKHT MT \& EBRAHIM-SARAIE HS. 2018. Molecular analysis of drug-resistant Acinetobacter baumannii isolates by ERIC-PCR. Meta Gene 17: 132-135.

LEE C-R, LEE JH, PARK M, PARK KS, BAE K, KIM YB, CHA C-J, JEONG $B C$ \& LEE SH. 2017. Biology of Acinetobacter baumannii: pathogenesis, antibiotic resistance mechanisms, and prospective treatment options. Front Cell Infect Microbiol 7: 55.

LI XM, CHOI JA, CHOI IS, KOOK JK, CHANG YH, PARK G, JANG SJ, KANG SH \& MOON DS. 2016. Development and evaluation of species-specific PCR for detection of nine Acinetobacter species. Ann Clin Lab Sci 46(3): 270-278.

LIMA AVA ET AL. 2020. Occurrence and diversity of intraand interhospital drug-resistant and biofilm-forming Acinetobacter baumannii and Pseudomonas aeruginosa. Microb Drug 26(7): 802-814.

LIOU ML, SOO PC, LING SR, KUO HY, TANG CY \& CHANG KC. 2014. The sensor kinase BfmS mediates virulence in Acinetobacter baumannii. J Microbiol Immunol Infect 47(4): 275-281.

LIU H, WU YQ, CHEN LP, GAO X, HUANG HN, QIU FL \& WU D-C. 2016. Biofilm-related genes: analyses in multi- antibiotic resistant Acinetobacter Baumannii isolates from Mainland China. Med Sci Monit 22: 1801-1807.

MAGIORAKOS AP ET AL. 2012. Multidrug-resistant, extensively drug-resistant and pandrug-resistant bacteria: an international expert proposal for interim standard definitions for acquired resistance. Clin Microbiol Infect 18(3): 268-281.

MARTINS AF \& BARTH AL. 2013. Acinetobacter multirresistente - um desafio para a saúde pública. Multidrugresistant Acinetobacter - a challenge for public health. Sci Med 23(1): 56-62.

MOREIRA RRB, VIANA GF, DE MORAES ACC, DE SOUZA BASTOS M, NISHIYAMA SAB, DOS ANJOS SZCZEREPA MM, CARDOSO CL \& TOGNIM MCB. 2018. Dissemination of Acinetobacter baumannii OXA-23 in old and new intensive care units without transfer of colonized patients. Infect Control Hosp Epidemiol 39(9): 1135-1137.
NEMEC A, KRIZOVA L, MAIXNEROVA M, SEDO O, BRISSE S \& HIGGINS PG. 2015. Acinetobacter seifertii sp. nov., a member of the Acinetobacter calcoaceticus-Acinetobacter baumannii complex isolated from human clinical specimens. Int J Syst Evol Micr 65: 934-942.

QI L ET AL. 2016. Relationship between antibiotic resistance, biofilm formation, and biofilm-specific resistance in Acinetobacter baumannii. Front Microbiol 7: 483-493.

REENA AAA, SUBRAMANIYAN A \& KANUNGO R. 2017. Biofilm formation as a virulence factor of Acinetobacter baumannii: An emerging pathogen in critical care units. J Curr Res Sci Med 3: 74-78.

ROMANIN P ET AL. 2019. Multidrug- and Extensively DrugResistant Acinetobacter baumannii in a Tertiary Hospital from Brazil: The importance of carbapenemase encoding genes and epidemic clonal complexes in a 10-year study. Microb Drug Resist 25(9): 1365-1373.

RUMBO-FEAL S ET AL. 2013. Whole Transcriptome Analysis of Acinetobacter baumannii Assessed by RNA-sequencing reveals different mRNA expression profiles in biofilm compared to planktonic cells. PLoS ONE 8(8): e72968.

RYU SY, BAEK WK \& KIM HA. 2017. Association of bioflm production with colonization among clinical isolates of Acinetobacter baumannii. Korean J Intern Med 32(2): 345-351.

SCHROEDER M, BROOKS BD \& BROOKS AE. 2017. The complex relationship between virulence and antibiotic resistance. Genes (Basel) 8(1): 39.

SILVA GJ \& DOMINGUES S. 2017. Interplay between Colistin Resistance, Virulence and Fitness in Acinetobacter baumannii. Antibiotics 6(4): 28.

SIQUEIRA CCM, GUIMARÃES AC, MATA TFD, PRATTE-SANTOS R, RAYMUNDO NLS, DIAS CF \& MORAES R. 2018. Prevalence and antimicrobial susceptibility profile of microorganisms in a university hospital from Vitória (ES), Brazil. J Bras Patol Med Lab 54(2): 76-82.

STEPANOVIC S, VUKOVIC D, DAKIC I, SAVIC B, SVABIC \& VLAHOVIC M. 2000. A modified microtiter-plate test for quantification of staphylococcal biofilm formation. J Microbiol Methods 40(2): 175-179.

TAYABALI AF, NGUYEN KC, SHWED PS, CROSTHWAIT J, COLEMAN G \& SELIGY VL. 2012. Comparison of the virulence potential of Acinetobacter strains from clinical and environmental sources. PLoS One 7(5): e37024.

THUMMEEPAK R, KONGTHAI P, LEUNGTONGKAM U \& SITTHISAK S. 2016. Distribution of virulence genes involved in 
bioflm formation in multi-drug resistant Acinetobacter baumannii clinical isolates. Int Microbiol 19: 121-129.

TURTON JF, GABRIEL SN, VALDERREY C, KAUFMANN ME \& PITT TL. 2007. Use of sequence-based typing and multiplex PCR to identify clonal lineages of outbreak strains of Acinetobacter baumannii. Clin Microbiol Infect 13(8): 807-815.

VIJAYAKUMAR S, BISWAS IB \& VEERARAGHAVAN B. 2019. Accurate identification of clinically important Acinetobacter spp.: an update. Future Sci OA 5(6): FSO395.

WASFI R, RASSLAN F, HASSAN SS, ASHOUR HM \& ABD EL-RAHMAN OA. 2021. Co-Existence of Carbapenemase-Encoding Genes in Acinetobacter baumannii from Cancer Patients. Infect Dis Ther 10(1): 291-305.

WONG D, NIELSEN TB, BONOMO RA, PANTAPALANGKOOR P, LUNA B \& SPELLBERG B. 2017. Clinical and pathophysiological overview of Acinetobacter infections: a century of challenges. Clin Microbiol Rev 30(1): 409-447.

WOODFORD N, ELLINGTON MJ, COELHO JM, TURTON JF, WARD ME, BROWN S, AMYES SGB \& LIVERMORE DM. 2006. Multiplex PCR for genes encoding prevalent OXA carbapenemases in Acinetobacter spp. Int J Antimicrob Agents 27(4): 351-353.

YANG Q, SCHULTZ GS \& GIBSON DJ. 2018. A surfactant-based dressing to treat and prevent Acinetobacter baumannii biofilms. J Burn Care Res 39(5): 766-770.

ZEIGHAMI H, VALADKHANI F, SHAPOURI R, SAMADI E \& HAGHI F. 2019. Virulence characteristics of multidrug resistant biofilm forming Acinetobacter baumannii isolated from intensive care unit patients. BMC Infect Dis 19(1): 629.

\section{How to cite}

SILVA AMCM, COSTA JÚNIOR SD, LIMA JLC, FARIAS FILHO JLB, CAVALCANTI IMF \& MACIEL MAV. 2021. Investigation of the association of virulence genes and biofilm production with infection and bacterial colonization processes in multidrug-resistant Acinetobacter spp.. An Acad Bras Cienc 93: e20210245. DOI 10.1590/0001-3765202120210245.

\section{ADRIANA MARIA C.M. DA SILVA ${ }^{1}$}

https://orcid.org/0000-0003-0726-3527

\section{SÉRGIO D. COSTA JÚNIOR ${ }^{1}$}

https://orcid.org/0000-0002-2501-3284

JAILTON L.C. LIMA'

https://orcid.org/0000-0002-5500-1129

JOSÉ LUCIANO B. DE FARIAS FILHO'

https://orcid.org/0000-0002-8252-0936

ISABELLA M.F. CAVALCANTI ${ }^{2}$

https://orcid.org/0000-0002-7889-3502

MARIA AMÉLIA V. MACIEL ${ }^{1}$

https://orcid.org/0000-0002-4220-6889

${ }^{1}$ Federal University of Pernambuco, Medical

Science Center, Av. Prof. Moraes Rego, 1235, Cidade

Universitária, 50670-901 Recife, PE, Brazil

${ }^{2}$ Federal University of Pernambuco, Laboratory of Immunopathology Keizo Asami (LIKA), Av. Prof. Moraes Rego, 1235, Cidade Universitária, 50670-901 Recife, PE, Brazil

Correspondence to: Isabella Macário Ferro Cavalcanti E-mail: isabella.cavalcanti@ufpe.br

\section{Author contributions}

AMCMS designed the study, executed the laboratorial methodology, analyzed the data and wrote the manuscript. SDCJ, JLCL and JLBFF have contributed by performing the phenotypical characterization of biofilm formation, PCR and antimicrobial assays. MAVM and IMFC have supervised the laboratory work and contributed with the critical evaluation of the manuscript. All authors have read and approved the article's submission.

\section{(cc) BY}

